\title{
Association between Free Sugars Intake and Excessive Daytime Sleepiness among Chinese Adolescents
}

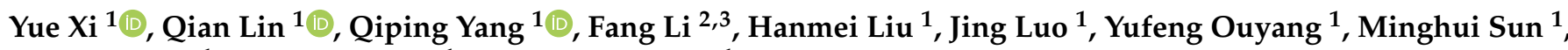 \\ Cuiting Yong ${ }^{1}$, Caihong Xiang ${ }^{1}$ and Wenya Zheng ${ }^{1, *}$ \\ 1 Department of Nutrition Science and Food Hygiene, Xiangya School of Public Health, \\ Central South University, 110 Xiangya Road, Changsha 410078, China; xiyue0404@csu.edu.cn (Y.X.); \\ linqian@csu.edu.cn (Q.L.); yangqiping12@csu.edu.cn (Q.Y.); hanmeiliu@csu.edu.cn (H.L.); \\ luojing2546@csu.edu.cn (J.L.); oyyf0102@csu.edu.cn (Y.O.); sun.1234@csu.edu.cn (M.S.); \\ yongcuiting@csu.edu.cn (C.Y.); xch0622@csu.edu.cn (C.X.) \\ 2 Department of Epidemiology and Health Statistics, Xiangya School of Public Health, \\ Central South University, Changsha 410078, China; lifang_csu@csu.edu.cn \\ 3 Hunan Provincial Key Laboratory of Clinical Epidemiology, Changsha 410078, China \\ * Correspondence: wenyazheng@csu.edu.cn; Tel.: +86-199-7985-1193
}

Citation: Xi, Y.; Lin, Q.; Yang, Q.; Li, F.; Liu, H.; Luo, J.; Ouyang, Y.; Sun, M.; Yong, C.; Xiang, C.; et al. Association between Free Sugars Intake and Excessive Daytime Sleepiness among Chinese Adolescents. Nutrients 2021, 13, 3959 https://doi.org/10.3390/nu13113959

Academic Editor: Kimber L. Stanhope

Received: 29 September 2021

Accepted: 3 November 2021

Published: 5 November 2021

Publisher's Note: MDPI stays neutral with regard to jurisdictional claims in published maps and institutional affiliations.

Copyright: (c) 2021 by the authors. Licensee MDPI, Basel, Switzerland. This article is an open access article distributed under the terms and conditions of the Creative Commons Attribution (CC BY) license (https:// creativecommons.org/licenses/by/ $4.0 /)$.

\begin{abstract}
This study aimed to investigate the prevalence of excessive daytime sleepiness (EDS) and explore the association between free sugars intake and EDS. In this cross-sectional study, a total of 1517 middle school students (808 boys and 707 girls) aged 12 14 years were recruited. The study was conducted in Changsha city, China. Adolescents completed an online questionnaire, including the Epworth Sleepiness Scale (ESS), sleep characteristics, a 12-item Food Frequency Questionnaire (FFQ), and other self-reported information. The ESS score $\geq$ ten was defined as EDS. The anthropometric indices, including height, weight, and waist circumference, were measured and recorded by uniformly trained assistants. Statistical analyses included the Chi-square test and binary logistic regression model. The mean ESS score and free sugars consumption were $6.8 \pm 3.9$ points and $53.1 \pm 44.7 \mathrm{~g} / \mathrm{d}$, respectively. The prevalence of EDS among adolescents was $22.5 \%$, and more girls than boys had EDS ( $26.1 \%$ vs. $19.4 \%, p<0.05)$. An exceeded free sugars intake was positively associated with EDS, with the adjusted Odds Ratio (OR) with its 95\% Confident Interval (95\% CI) of $1.366(1.060 \sim 1.761, p<0.05)$. EDS and excessive consumption of free sugars are commonly found among Chinese adolescents. Further studies are needed to confirm whether free sugars restriction can be meaningful to improve daytime drowsiness in those with EDS.
\end{abstract}

Keywords: adolescent; dietary sugars; sugar-sweetened beverages; excessive daytime sleepiness; sleep hygiene

\section{Introduction}

Excessive daytime sleepiness (EDS) is characterized by difficulty maintaining wakefulness and an increased tendency to fall asleep during the day, even after a whole night's sleep [1]. Excessive sleepiness during the daytime is a common phenomenon worldwide nowadays. The prevalence of EDS ranged from 2.5 to $15.3 \%$ in the general adults [2-5]. It is estimated that over $40 \%$ of adolescents suffer from EDS [6,7]. In China, around $10.3 \%$ of adolescents higher than the 7th grade struggle with EDS [8]. As a public health concern, EDS is associated with various adverse consequences, including poor academic performance, mental health, accidental injury, and even adult crime [9-12].

EDS is related to several factors, including short sleep duration, obesity, depression, and screen time, etc. [2,13-17]. Apart from the above-known associations, the relationship between dietary patterns, especially sugar intake, and EDS is increasingly recognized. C. Anderson and J.A. Horne have revealed that high sugar content and low caffeine drinks would not alleviate sleepiness but rather worsen it [18]. Katagiri R et al. [19] suggested that 
high carbohydrate meals, including energy drinks and sugar-sweetened beverages, were associated with self-reported poor-quality sleep. A study by St-Onge et al. [20] showed that high-sugar intake was associated with less restorative sleep and more arousal, leading to EDS. The relationship between sugary drinks and sleep has been studied, but our understanding remains insufficient. Sugar-sweetened beverages (SSBs) were the primary contributors of dietary sugars. Within dietary sugars, it is free sugars that proved to be pivotal in impairing health, particularly in developing chronic diseases [21]. The term free sugars, as used by the World Health Organization (WHO) in its report, encompassed "all mono and disaccharides added to food by manufacturer, cook or consumer plus those sugars naturally present in honey, syrups and fruits juices, and concentrates" [21]. WHO recommended that, in both adults and children, the free sugars intake should reduce to less than $10 \%$ of total energy intake [21]. One genuine concern, up to now, is the growing consumption of free sugars. Free sugars intake of adolescents in Latin American countries ranged from 58.2 to $106.9 \mathrm{~g} / \mathrm{d}$ [22], and in China with $22.5 \mathrm{~g} / \mathrm{d}$ in 2012 [23] to $53.1 \mathrm{~g} / \mathrm{d}$ in 2019 [24]. Commonly, free sugars intake accounted for more than $10 \%$ of energy in the diets [25]. Despite the growing number of studies conducted on sugar intake and sleepiness, the evidence mainly focused on EDS, dietary carbohydrates, and dietary SSBs [24-28], and the research on both free sugars intake and free sugars consumption frequency with sleepiness is relatively scarce.

Adolescence is a particular period for adulthood development and lifelong health $[29,30]$. During puberty, significant changes appear in sleep patterns due to biological factors, environmental factors, and social demands, increasing this fragility for the emergence of inadequate sleep [31], which could directly lead to EDS. Along with perceived study stress, physical inactivity, and more sedentary behaviors, adolescents might consume sugary foods and SSBs [32] more frequently for refreshment, responding to stress, or alleviating depressive and anxiety emotions [33,34]. All these factors might impair control of overeating sweets [35], contributing to the increased consumption of sugars by adolescents worldwide [25]. Despite the increasing interest in understanding sleep patterns and diet, studies conducted on this age group are limited.

To our best knowledge, no study has yet examined free sugars intake and its association with EDS in adolescents. Given that puberty is suggested to be a "critical period" for developing various diseases in later life, and dietary habits have been shown to track into adulthood, it is vital to explore the relationship between EDS and free sugars intake during this specific period. Thus, this study aims to investigate the prevalence of EDS and its association with free sugars intake among 12 14-year-old adolescents in China. We hypothesized that the consumption of free sugars is positively associated with EDS.

\section{Materials and Methods}

\subsection{Ethical Approval}

The study was approved by the Ethics Review Committee of the Xiangya School of Public Health, Central South University (XYGW-2019-025).

\subsection{Study Design and Participants}

From March to July 2019, we conducted this study in Changsha, the capital city of Hunan Province in south-central China. Ten middle schools from five districts (Yuhua, Tianxin, Furong, Kaifu, and Yuelu District) were selected using two-stage stratified random cluster sampling methods. Two middle schools were randomly sampled from each district. According to the inclusion and exclusion criteria, the 7th- and 8th-grade students were recruited when: (1) schools agreed to participate with more than 500 students, and (2) parents or caregivers agreed to participate, and consented to the collection of information. The exclusion criteria was the inability to read or write the questionnaire.

The protocol was submitted to the local Education Bureau for permission to conduct this investigation. With the education bureau's assistance, we contacted leaders of the selected schools and then delivered the consent forms to students as homework. If parents 
or caregivers signed informed consent, the students were enrolled. A total of 1517 students completed the questionnaire (Valid response rate $=100 \%$ ).

\subsection{Measures}

The survey included an online questionnaire and anthropometric measurements.

\subsubsection{Questionnaire Survey}

The students were guided to complete the online questionnaire by uniformly trained research assistants in the schools' computer room. The Questionnaire Star, an online questionnaire tool, was used to develop and deliver the investigation questionnaire. Each questionnaire had a unique linkage. We collected students' demographics information, free sugars consumption, excessive daytime sleepiness, sleep characteristics, physical activities, sedentary and screen time, and laryngopharyngeal reflux symptoms.

- Demographic information: Students' sex, age, sibling status (the only child or not), domicile place, and family monthly income were collected.

- Free Sugars Consumption: Free sugars consumption was collected by a food frequency questionnaire (FFQ) focused on sugar-sweetened beverages and sweetened foods. The FFQ was modified based on the two previous studies conducted by the Center for Diseases Control and Prevention of China (China's CDC) and the result of the pilot study [36]. In the current study, SSBs consisted of carbonated drinks (also named sodas), vegetable protein drinks, juice or juice drinks, tea or tea drinks, sports drinks, and bubble tea. Sugary foods included cakes, desserts, candy (chocolate, Snickers and Maltesers, etc.), and preserved fruits (dried or candied fruits). We also set honey and flavored milk/yogurt as sources of free sugars. The response options of the average intake of SSBs and sugary foods included " $100 \mathrm{~mL} /$ time, $200 \mathrm{~mL} /$ time, $300 \mathrm{~mL} / \mathrm{time}$, $400 \mathrm{~mL} / \mathrm{time}$, and $500 \mathrm{~mL} / \mathrm{time}$ " and " $25 \mathrm{~g} / \mathrm{time}, 50 \mathrm{~g} /$ time, $75 \mathrm{~g} /$ time, $100 \mathrm{~g} / \mathrm{time}$, $150 \mathrm{~g} /$ time, and $200 \mathrm{~g} /$ time" $^{\prime \prime}$, respectively.

- $\quad$ Excessive Daytime Sleepiness: The Epworth Sleepiness Scale (ESS) $[37,38]$ was used to assess EDS. The ESS contained eight items that measure the probability of doze in different situations, with four responses scored from " 0 " to " 3 ". The results of ESS ranged from 0 to 24 , with high scores reflecting high levels of sleepiness. In this study, ESS $\geq 10$ was defined as EDS [39].

- $\quad$ Sleep Characteristics: Self-reported sleep characteristics, including sleep duration on weekdays and weekends, were obtained by three self-designed questions, including (1) In the last month, how many hours did you sleep on weekdays on average during a 24-h period? (2) In the last month, how many hours did you sleep on weekends on average during a 24-h period? The response options of these two questions ranged from "less than six hours" to "more than eight hours." (3) How would you describe your sleep quality in the last month? Students could choose their answers from five options, categorized from "very good" to "moderate" to "very bad."

- Physical activities: The short form of the International Physical Activity Questionnaire (IPAQ-short form) [40] was used to assess physical activity. The overall index of metabolic equivalent (MET, min/week) was used to present the intensity of physical activity. According to the recommended categorical scoring, students' physical activity levels were divided into three groups: low activity (inactivity), moderate activity, and high activity.

- Sedentary time and screen time: Sedentary time was collected from IPAQ-SF, by asking "In the last seven days, how many minutes of the working days did you sit?" The answers were converted from minutes into hours, and according to WHO [41], sitting time $>8 \mathrm{~h}$ was defined as sedentary. Similarly, screen time was assessed by asking, "In the last seven days, how many minutes of the working days (or weekends) were you in front of the screen?" We then converted the answers into hours and took the mean of the total hours of workdays and weekends screen time as the daily screen 
time. Screen time $>2 \mathrm{~h}$ per day was categorized into longer screen time according to WHO [41].

- Laryngopharyngeal Reflux Symptoms (LPR symptoms): Symptoms were also assessed using the reflux symptom index (RSI) [42]. The RSI consists of 9 items with a 6-point response scale (from "No problem $=0$ " to "Severe problem $=5$ "). RSI scores ranged from 0 to 45; the higher the RSI score, the more severe the LPR symptoms. In this study, the RSI greater than 13 was identified as abnormal and likely LPR symptoms [42].

\subsubsection{Anthropometric Measurements}

Conducted by uniformly trained research assistants, the height was measured by the standard height meter and weight by TANITA human body composition analyzer BCW02C (Guangdong Food and Drug Administration (prospective), No. 2210704, 2014). The waist circumference (WC) was measured by calibrated flexible non-stretch tape laid. Body mass index (BMI) was calculated by dividing body weight $(\mathrm{kg})$ by height squared $\left(\mathrm{m}^{2}\right)$. Participants were classified as the standard and overweight/obese group based on the age- and sex-specific BMI cut-off values for Chinese children and adolescents (6 18 years old) [43]. Based on the age- and sex-specific cut-off values [44], the WC was grouped into three as normal $\left(<\mathrm{P}_{75}\right)$, normal-high $\left(\mathrm{P}_{75}-\mathrm{P}_{90}\right)$, and high $\left(>\mathrm{P}_{90}\right)$.

\subsection{Free Sugars Intake Assessments}

The primary sources of free sugars were derived from SSBs, and sweetened foods included in the 12-item FFQ mentioned above. The response options of FFQ were converted to daily consumption frequencies as follows: $0=$ "once a month or less", 0.14 times/day $=$ "once a week", 0.36 times $/$ day $=$ "2 3 times a week", 0.64 times $/$ day $=$ " $4 \sim 5$ times a week" and 2 times/day $=$ " 2 times/day or more".

The following formula (1) calculated the individual's estimated daily intake of free sugars [24]:

$$
Z=A\left(f_{1}\right) \times \frac{A\left(i_{1}\right)}{7} \times c_{1}+B\left(f_{2}\right) \times \frac{B\left(i_{2}\right)}{7} \times c_{2}+\ldots+X\left(f_{n}\right) \times \frac{X\left(i_{n}\right)}{7} \times c_{n}
$$

daily consumption of free sugars $(Z, \mathrm{~g} / \mathrm{d})$; food types $(A, B, \cdots, X)$; frequency $(f$, times $/ \mathrm{d})$; intake of each time ( $i$, g, or $\mathrm{mL})$; free sugars content from China CDC database $(c, \mathrm{~g} / 100 \mathrm{~g}$ or $\mathrm{mL} / 100 \mathrm{~mL}$; shown in Table A1), and $n$ is a natural number. For certain foods absent from the database, the average sugar content of such foods was used as a substitution. According to the recommendation of the latest China's dietary guidelines [45], students were divided into normal- and high-sugar consumption groups (50 $\mathrm{g}$ as the cut-off values).

\subsection{Statistical Analyses}

EpiData 3.0 software (The Epi Data Association, Odense, Denmark) was used for data entry, the IBM SPSS 24.0 software (IBM Corp., Armonk, NY, USA) was used for data analyses. Descriptive data were presented as a percentage or the mean with standard deviation. We used the Chi-squared test and non-parametric tests to analyze related variates for different groups. Binary logistic regression analysis was used to analyze the association between free sugars intake and EDS. The explanatory variables with $p<0.10$ were included in the multivariate analyses by the binary logistic regression's backward stepwise method. Significant levels were set at $p<0.05$.

\section{Results}

\subsection{Characteristics of Participants}

There were 1517 students in 7th and 8th grade who participated in this cross-sectional study. Of these, $46.7 \%$ were girls, and $47.3 \%$ were 12 years old (Table 1 ). Overall, $55.3 \%$ were only children, and $92.2 \%$ were day-students. There were $27.3 \%$ of students who were overweight or obese, $21.7 \%$ with normal-high waist circumference, and $24.1 \%$ with high waist circumference. The average consumption of free sugars was $53.1 \pm 44.7 \mathrm{~g} / \mathrm{d}$ 
in the current study. Higher the grade, more the free sugars consumed $(40.2 \%$ vs. $46.5 \%$, $p=0.013)$. Compared with day-students, those who live in dormitories consumed more free sugars $(42.3 \%$ vs. $54.2 \%, p=0.012)$.

Table 1. Characteristics of adolescents by outcome variables $(n=1517$, mean $\pm S D)$.

\begin{tabular}{|c|c|c|c|c|c|}
\hline Variables & $\begin{array}{c}\text { Total } \\
(n=1517)\end{array}$ & $\begin{array}{c}\text { High Free Sugars Intake } \\
(656,43.2 \%)\end{array}$ & $p$ & $\begin{array}{c}\text { EDS } \\
(342,22.5 \%)\end{array}$ & $p$ \\
\hline \multicolumn{3}{|l|}{ Sex } & \multicolumn{2}{|l|}{0.130} & 0.002 \\
\hline Boy & $808(53.3)$ & $364(45.0)$ & & $157(19.4)$ & \\
\hline Girls & $709(46.7)$ & $292(41.2)$ & & $185(26.1)$ & \\
\hline \multicolumn{3}{|l|}{ Age } & \multirow[t]{4}{*}{0.085} & & \multirow[t]{4}{*}{0.461} \\
\hline 12 & $396(26.1)$ & $154(38.9)$ & & $81(20.5)$ & \\
\hline 13 & $717(47.3)$ & $314(43.8)$ & & $170(23.7)$ & \\
\hline 14 & $404(26.6)$ & $188(46.5)$ & & $91(22.5)$ & \\
\hline \multicolumn{3}{|l|}{ Grade } & \multirow[t]{3}{*}{0.013} & & \multirow{3}{*}{0.117} \\
\hline 7th & $784(51.7)$ & $315(40.2)$ & & $164(20.9)$ & \\
\hline 8 th & $733(48.3)$ & $341(46.5)$ & & $178(24.3)$ & \\
\hline \multicolumn{3}{|l|}{ Only child } & \multicolumn{2}{|l|}{0.393} & \multirow[t]{3}{*}{0.470} \\
\hline Yes & $839(55.3)$ & $285(42.0)$ & & $195(23.2)$ & \\
\hline No & $678(44.7)$ & $371(44.2)$ & & $147(21.7)$ & \\
\hline \multicolumn{3}{|l|}{ Live in or out } & \multirow[t]{3}{*}{0.012} & & \multirow[t]{3}{*}{0.582} \\
\hline Dormitory & $118(7.8)$ & $64(54.2)$ & & $313(22.4)$ & \\
\hline Home & $\begin{array}{l}1399 \\
(92.2)\end{array}$ & $592(42.3)$ & & $29(24.6)$ & \\
\hline \multicolumn{3}{|c|}{ Family Monthly Income \# } & \multicolumn{2}{|l|}{0.042} & \multirow[t]{4}{*}{0.065} \\
\hline Low & $616(40.6)$ & $251(40.7)$ & & 117 (19.5) & \\
\hline Medium & $542(35.7)$ & $230(42.4)$ & & $139(25.1)$ & \\
\hline High & 359 (23.7) & 175 (48.7) & & $86(23.6)$ & \\
\hline \multicolumn{3}{|l|}{ BMI Status } & 0.243 & & \multirow[t]{3}{*}{0.081} \\
\hline Normal & $\begin{array}{l}1103 \\
(72.7)\end{array}$ & $487(44.2)$ & & $236(21.4)$ & \\
\hline $\mathrm{OW} / \mathrm{OB}$ & $414(27.3)$ & $169(40.8)$ & & $106(25.6)$ & \\
\hline \multicolumn{3}{|l|}{$\begin{array}{l}\text { Waist } \\
\text { circumference }\end{array}$} & 0.100 & & \multirow[t]{4}{*}{0.009} \\
\hline Normal & $822(54.2)$ & $376(45.7)$ & & $162(19.7)$ & \\
\hline Normal-high & $329(21.7)$ & $134(40.7)$ & & $91(27.7)$ & \\
\hline High & $366(24.1)$ & $146(39.9)$ & & 89 (24.3) & \\
\hline
\end{tabular}

Compared by Chi-square test. BMI status: grouped by age- and sex-specific BMI cut-off values. High free sugars intake: free sugars intake $>50 \mathrm{~g} / \mathrm{d}$. EDS: ESS score $\geq 10$. OW/OB: overweight/obese. Family monthly income: low (<5000 RMB), middle (5000-9000 RMB), high (>9000 RMB). RMB: Renminbi, Chinese official coupons, $1 \mathrm{RMB} \approx 0.15 \mathrm{USD}$. \# Data with missing values, the information presented in Table 1 is the imputation results. Sensitivity analysis was conducted for confirmation (Table A2).

The mean ESS score was $6.79 \pm 3.88$. The prevalence of EDS among adolescents was $22.5 \%$ (Table 1 ). More girls than boys tended to be sleepy during the daytime ( $26.1 \% \mathrm{vs.}$ $19.4 \%, p=0.002)$. Students with normal-high waist circumference accounted for a higher proportion of EDS than those with normal ones $(27.7 \%$ vs. $19.7 \%, p=0.009)$.

\subsection{Sleepiness Related Factors among 12 14 Years Adolescents by Free Sugars Intake}

Based on the Dietary Guidelines for Chinese Residents (2016), it would be appropriate for adults to consume no more than $50 \mathrm{~g}$ of added sugars, and the preferable level of sugars intake was below $25 \mathrm{~g} / \mathrm{d}$. In the present study, $43.2 \%$ of the students consumed free sugars higher than the recommended max level (Table 2). Overall, $50.3 \%$ of the adolescents with EDS were high free sugar consumers, compared with $41.2 \%$ of those without EDS $(p=0.003)$. There was a significant tendency for shorter sleep duration with increasing free sugars intake (weekday sleep duration: $p_{\text {-trend }}=0.004$, and weekend sleep duration: $\left.p_{\text {-trend }}=0.005\right)$. The median score of the overall MET was $1375.0 \mathrm{~min} /$ week. More than onefourth of the participants (29.3\%) were physically inactive, and only $22.7 \%$ were physically 
active. Among these students, $8.1 \%$ had symptoms of laryngopharyngeal reflux. The free sugars intake of students with LPR symptoms was significantly higher than those who did not have LPR symptoms ( $56.1 \%$ vs. $42.1 \%, p=0.003$ ). The longer the adolescents' screen time, the higher the free sugars intake $(47.8 \%$ vs. $36.1 \%, p=0.001)$. We did not observe the difference in self-reported sleep quality, physical activity, and sedentary time by free sugars intake level among this population. In addition, adolescents' EDS varied significantly by sleep duration, self-reported sleep quality, and LPR symptoms (Table A3).

Table 2. EDS Related Factors by the level of free sugars intake ( $n=1517 \%$ ).

\begin{tabular}{|c|c|c|c|c|}
\hline \multirow[b]{2}{*}{ Variables } & \multirow[b]{2}{*}{$\begin{array}{c}\text { Total } \\
(n=1517)\end{array}$} & \multicolumn{2}{|c|}{ Free Sugars Intake } & \multirow[b]{2}{*}{$p$} \\
\hline & & $\begin{array}{c}\leq 50 \mathrm{~g} / \mathrm{d} \\
(861,56.8 \%)\end{array}$ & $\begin{array}{c}>50 \mathrm{~g} / \mathrm{d} \\
(656,43.2 \%)\end{array}$ & \\
\hline \multicolumn{4}{|c|}{ Excessive Daytime Sleepiness (EDS) } & 0.003 \\
\hline EDS & $342(22.5)$ & $170(49.7)$ & $172(50.3)$ & \\
\hline No EDS & $1175(77.5)$ & $691(58.8)$ & $484(41.2)$ & \\
\hline \multicolumn{5}{|l|}{ Sleep Duration } \\
\hline On Workdays & & & & 0.005 \\
\hline$<6 \mathrm{~h}$ & $145(9.6)$ & $65(44.8)$ & $80(55.2)$ & \\
\hline $6 \sim 8 \mathrm{~h}$ & $1061(69.9)$ & $607(57.2)$ & $454(42.8)$ & \\
\hline$>8 \mathrm{~h}$ & $311(20.5)$ & $189(60.8)$ & $122(39.2)$ & \\
\hline On Weekends & & & & 0.006 \\
\hline$<6 \mathrm{~h}$ & $84(5.5)$ & $35(41.7)$ & $49(58.3)$ & \\
\hline $6 \sim 8 \mathrm{~h}$ & $593(39.1)$ & $329(55.5)$ & $264(44.5)$ & \\
\hline$>8 \mathrm{~h}$ & $840(55.4)$ & $497(59.2)$ & $343(40.8)$ & \\
\hline \multicolumn{4}{|c|}{ Self-reported Sleep Quality } & 0.072 \\
\hline Low & $284(18.7)$ & $144(50.7)$ & $140(49.3)$ & \\
\hline Moderate & $497(32.8)$ & $291(58.6)$ & $206(41.4)$ & \\
\hline High & $736(48.5)$ & $426(57.9)$ & $310(42.1)$ & \\
\hline \multicolumn{4}{|c|}{ Laryngopharyngeal Reflux Symptoms } & 0.003 \\
\hline No & $1394(91.9)$ & 807 (57.9) & $587(42.1)$ & \\
\hline Yes & $123(8.1)$ & $54(43.9)$ & $69(56.1)$ & \\
\hline \multicolumn{4}{|l|}{ Physical Activities } & 0.176 \\
\hline Low & $445(29.3)$ & $253(56.9)$ & $192(43.1)$ & \\
\hline Medium & $728(48.0)$ & $427(58.7)$ & $301(41.3)$ & \\
\hline High & $344(22.7)$ & $181(52.6)$ & $163(47.4)$ & \\
\hline \multicolumn{4}{|l|}{ Screen Time } & $<0.001$ \\
\hline$\leq 2 \mathrm{~h}$ & $595(39.2)$ & $380(63.9)$ & $215(36.1)$ & \\
\hline$>2 \mathrm{~h}$ & $922(60.8)$ & $481(52.2)$ & $441(47.8)$ & \\
\hline \multicolumn{4}{|l|}{ Sedentary Time } & 0.345 \\
\hline$\leq 8 \mathrm{~h}$ & $1138(75.0)$ & $638(56.1)$ & $500(43.9)$ & \\
\hline$>8 \mathrm{~h}$ & $379(25.0)$ & $223(58.8)$ & $156(41.2)$ & \\
\hline
\end{tabular}

Free sugars intake was different in total ESS scores (Table A4). The ESS scores of the adolescents who overeat free sugars of $50 \mathrm{~g} / \mathrm{d}$ were 7.20, almost one point higher than that of students who did not. Additionally, free sugars intake is also differential in the specific item of the Epworth Sleepiness Scale. When sitting and reading, sitting and talking to someone, sitting quietly after a lunch without alcohol, and in a car while stopped for a few minutes in the traffic, students who consumed more free sugars tended to obtain a higher ESS score.

\subsection{The Association between Free Sugars Intake and EDS among Observed Adolescents}

The binary logistic regression model was used to explore the association between free sugars intake and EDS (Table 3). Students who indulged in free sugars more than those with a relatively low intake were inclined to consider dozing during the daytime $(\mathrm{OR}=1.366$, 95\% CI: 1.060 1.761, $p<0.05$ ). Considering different sources of free sugars (Table A5), students who more frequently consumed SSBs (OR $=1.525,95 \%$ CI: $1.160 \sim 2.005, p<0.05)$, 
desserts (OR $=1.333,95 \%$ CI: 1.017 1.748, $p<0.05)$, or confectioneries $(\mathrm{OR}=1.613,95 \%$ CI: 1.241 2.097, $p<0.05)$ found it easier to be sleepy during the daytime. Separating SSBs into parts, drinking vegetable protein beverages more than one time a week $(\mathrm{OR}=1.460$, $95 \%$ CI: 1.085 1.965, $p<0.05)$ seems to be a risk factor of EDS. The associations between vegetable protein beverage ( $\mathrm{OR}=1.439,95 \% \mathrm{CI}$ : $1.054 \sim 1.964, p<0.05)$, confectioneries $(\mathrm{OR}=1.548,95 \% \mathrm{CI}: 1.178 \sim 2.035, p<0.05)$, and EDS remained after adjustment.

Table 3. Binary Logistic regression model of association between free sugars intake and EDS among adolescents (No EDS as the reference, $n=1517$ ).

\begin{tabular}{ccc}
\hline Variables & Crude OR (95\% CI) & Adjusted OR (95\% CI) \\
\hline Free Sugars Intake $(\leq 50 \mathrm{~g}=$ ref) & $1.444(1.134,1.839)^{* *}$ & $1.366(1.060,1.761)^{*}$ \\
Sleep Duration $(<6 \mathrm{~h}=$ ref) & $0.641(0.510,0.806)^{* * *}$ & $0.880(0.676,1.145)$ \\
On workdays & $0.836(0.687,1.018)$ & $0.992(0.798,1.232)$ \\
On weekends & & \\
Night Sleep Quality (Poor $=$ ref) & $0.517(0.375,0.712)^{* * *}$ & $0.573(0.411,0.800)^{* *}$ \\
$\quad$ Neutral & $0.363(0.267,0.494)^{* * *}$ & $0.431(0.308,0.603)^{* * *}$ \\
$\quad$ Good & $3.619(2.482,5.277)^{* * *}$ & $3.002(2.026,4.446)^{* * *}$ \\
LPR symptoms (No = ref) &
\end{tabular}

*** $p<0.001,{ }^{* *} p<0.01$, and * $p<0.05$. EDS: ESS score $\geq 10$. No EDS: ESS score $<10$. Adjusted by sex, age, BMI status, and waist circumference, and screen time. LPR symptoms: RSI $\geq 13$.

\section{Discussion}

The ESS scores and free sugars intake among 12 14-year-old Chinese adolescents were relatively high. It is worth noting that high consumption of free sugars was associated with a high score of EDS. Adolescents who are more senior, living in the dormitory during school years, having shorter sleep duration, and accompanied with LPR symptoms tend to consume more sugary foods and SSBs and hence might have a higher risk of EDS. Although the research related to free sugars intake and EDS is insufficient, this study suggests a need for sugar intake reduction and sleep improvement in middle school students, plus a possible link between the two.

In the current study, the prevalence of EDS was $22.5 \%$ among adolescents, lower than Brazilian students of $47.6 \%$ [46], California students with 25\% [47], and Polish teens with $36.1 \%$ [12], but higher than that of the students in Korea with $15.9 \%$ in 2001 and $19.3 \%$ in 2014 [32,48]. This may be due to the different criteria for EDS (cut-off value as ten or eleven) [32,47,48], the physiological difference among races [46], local lifestyles [47], school shift [46], or to other factors. Compared with studies conducted in China, the prevalence of EDS is also lower than that of the students in Hong Kong of $29.7 \%$ at Tanner stage 3 [49], Guangdong students with 27.6\% [8], and Shandong adolescent girls with $42.7 \%$ [50]. These discrepancies could be explained by different measure tools [8,49,50], course scheduling [11], and socio-cultural and economic characteristics [8] of each region of China. Consistent with the previous studies [6,12,46,50-52], our results verified that EDS is positively associated with females, insufficient sleep, and poor sleep quality. Taken together, these studies revealed that the issue of EDS is widespread among adolescents at home and abroad.

Our results presented that an exceeded free sugars intake is associated with short sleep duration, the influential factors of EDS. Similar findings suggested that poor dietary behaviors related to poor sleep were also observed in other countries [53,54]. A randomized crossover trial has demonstrated that sugar intake among adults led to significantly impaired sleep with more waking episodes and less restorative sleep [20]. Poor sleep would lead to EDS and deficient daytime functioning. As such, it is possible that adolescents who have an insufficient sleep seek out more sugars and caffeine to stay awake [54]. It is also argued that shorter sleep durations and EDS among adolescents might lead to an energy deficit, leading to higher consumption of energy/caloric dense foods in response [55]. Another explanation is that those sleepy adolescents may be less active due to fatigue and thus spend more time on sedentary activities such as mobile phones, which is also 
likely associated with the high consumption of sugary foods [54]. This could be reflected by our results that longer screen time is associated with higher free sugars intake. Even though the mechanisms relating short sleep duration to the consumption of sugars are not well understood, findings on this topic highlight the need for tailored education programs concerning good sleep hygiene and healthy eating habits in adolescents.

One significant finding of this study is the positive association between free sugars intake and EDS. Compared with the total dietary free sugars, earlier studies paid more attention to SSBs [54-56]. Consistently, our results showed that higher consumption of SSBs correlated with a higher risk of EDS [53-56]. Taking Chinese Confucianism tradition and intrinsic socio-cultural values, adolescents in China may be more vulnerable to study stress and peer pressure [57]. In order to stay up later to learn more, SSBs, especially caffeine beverages, might be more convenient drinks available to youths at midnight rather than fruits or vegetables [56]. Such access to SSBs might lead to EDS due to the stimulation properties of sugars and caffeine, and which, when consumed near bedtime, may affect adolescents' sleep. Apart from SSBs, the primary sources of free sugars among Chinese adolescents were flavored milk/yogurt and confectionery [24]. In line with other research $[19,54]$, confectionery is another risk factor of EDS. However, the association of flavored milk/yogurt with EDS was not observed in our investigation. Nevertheless, the relationship between free sugars intake and EDS may create a vicious cycle contributing to an unhealthy diet and chronic sleep issues [13,54,56].

As for the various types of SSBs, it is noteworthy that vegetable protein drinks (also named plant protein beverages) were a risk factor of EDS. Plant protein beverages are based on plants alternating to cow's milk [58]. An increasing number of traditional plantbased beverages are known worldwide, such as soymilk, coconut milk, oat milk, etc. It is generally believed in China that nuts such as walnut and almond are beneficial to promote memory $[59,60]$. Additionally, compared with tea or bubble tea, known as rich in caffeine, the consumers tend to assume that plant protein beverages, usually named "milk", are "healthy". All these situations might contribute to a higher consumption frequency of plant beverages. However, the large discrepancy in nutrients of these products and their bioavailability compared to milk or water was discrepant. For instance, the protein content of non-fortified homemade almond drinks is much lower (about 85\%) than cow's milk, and sometimes syrups or sucrose might be added for flavor promotion [61]. A possible explanation for this association is the amino acid Tryptophan present in plant beverages, which stimulates sleepiness after the ingestion $[62,63]$. Another interpretation might finally come down to the impact of excessive free sugars content in these plant protein beverages on EDS. Unfortunately, studies specifically addressing the relation between plant drink consumption and sleep impact in children and adolescents are limited [58]. In light of the thriving acceptance and consumption of plant beverages, the impact of free sugars intake, especially plant drinks, on adolescents' health should be of concern.

Along with the factors mentioned above, the coronavirus disease 2019 (COVID-19) pandemic would be another issue regarding adolescents' consumption of sugars and EDS. Studies revealed longer sedentary and screen time and higher prevalence of sleep and emotional problems during the COVID-19 pandemic than ever before [64-66]; under this stress state, people tend to consume more energy-dense foods to soothe negative emotions [67-70], and a higher intake of sugary foods could lead to weight gain or obesity, as well as EDS. Amongst all groups, youths were particularly prone to lifestyle and dietary changes during the COVID-19 pandemic [71]. This bi-directional relationship might create another vicious cycle, affecting adolescents living habits and eating behaviors, tracking into later life stages, and contributing to their lifelong health [71]. Hence, though we did not investigate the free sugars consumption during the COVID-19 pandemic period, living in the post-pandemic era with the new normal characterized by "social distancing" and "shelter in place" [71], it is significant to put new emphasis on implementing healthy eating habits. 
One notable finding in our study was that, though WC was associated with EDS in univariate analysis, we did not observe the association between obesity, WC, and EDS after adjustment. These findings seem contradictory with major related studies [72-74] but are similar to the previous $[8,75,76]$. There might be several plausible interpretations. First, in the relation between obesity and EDS, pubertal status is a vital covariate to consider. Puberty marks considerable changes in sleep and circadian patterns and sex differences regarding changes in body composition, metabolism, and endocrinology that could shape the influence of sleep on BMI [77] and may serve as a viable explanation for null findings in samples [74]. Second, it is suggested that traditional measures of abdominal obesity have been shown to correlate poorly with sleep disturbances [78]. Third, earlier studies regarding weight gain and EDS were mainly focused on the general adult population, while the present study was conducted in adolescents [8]. Finally, EDS is assumed to be the consequence of obstructive sleep apnea (OSA) [2], a sleep disorder characterized by repetitive episodes of upper airway obstruction, which appears to form a vicious cycle with obesity where each worsens another. The relation among obesity, EDS, and OSA is complex, which might sometimes be presented as a negative, or irrelevant association [2,75]. Though the mechanism of EDS remains unclear, obesity and free sugars intake among adolescents are the two challenging public health problems. Health professionals, parents, and teachers, playing pivotal roles in disseminating health messages, should be aware of the potential link between sugar reduction and sleep promotion as early possible.

This is the first study that focused on the association between free sugars intake and EDS. The major strength of the present study is the relatively large samples and standard quality control. Each participant's weight, height, and WC were assessed and recorded by uniformly trained assistants; this guaranteed the reliability of the anthropometric information. Additionally, we used the Epworth Sleepiness Scale to determine daytime drowsiness, making results more comparable and credible. Moreover, under the supervision of the teacher and project assistants, participants had to complete the questionnaire before submitting it to ensure data integrity.

However, interpretation of the findings in our study should consider some limitations. First, due to the cross-sectional design of this study, the causal relationship between free sugars intake and EDS may not be identified. This study was conducted on adolescents in a capital city of central-south China; thus, the findings may not be extrapolated to adolescents in rural or other parts of China. Furthermore, the free sugars intake was measured using an FFQ, and some sources of free sugars in this FFQ were absent, such as caffeine beverages or sucrose in homemade dishes; this could not accurately reflect the actual consumption of free sugars. Furtherly, the FFQ we used did not distinguish the beverages that contained the free sugars from those that did not, which would overestimate the adolescents' free sugars intake. Moreover, sleep characteristics, screen time, and sedentary time were assessed by a self-report questionnaire, which would lose some information. Sleep habits are a dynamic biological process regulated by the circadian system, and a single measure may not capture the full effects of sleep duration on EDS. Finally, admittedly, missing values may bias the results, despite the sensitivity analysis showing that the association between EDS and family monthly income (variables with missing data) were similar before and after imputation.

\section{Conclusions}

In this study, we found that both the prevalence of EDS and the consumption of free sugars were high. High consumption of free sugars was associated with a high score of EDS, and consuming SSBs and confectionery more frequently is associated with a higher risk of EDS among adolescents. Examining factors related to EDS in this vulnerable group is urgently needed. Improving the food environments in family and school and limiting the availability of SSBs, especially caffeine beverages and sugary foods, would be essential for addressing excessive free sugars consumption among adolescents and might alleviate students' EDS. Further research should focus more on dietary patterns, eating habits, and 
their relationship with sleep problems. A high-quality prospective study including a large sample should be conducted to clarify the causal association between dietary sugars and EDS or other sleep problems.

Author Contributions: Conceptualization and methodology, Y.X. and Q.Y.; software and validation, Q.Y.; formal analysis, W.Z., F.L. and Y.X.; investigation, Q.Y., H.L., J.L., Y.O., M.S., Y.X., C.Y. and C.X.; resources, Q.L. and Q.Y.; data curation, Q.Y., Y.X. and F.L.; writing-original draft preparation, Y.X., W.Z. and Q.L.; writing—review and editing, Y.X., W.Z. and Q.L.; supervision, Q.L. and Q.Y.; project administration, Q.L., Q.Y. and W.Z.; and funding acquisition, Q.L. and Y.X. All authors interpreted the results and made a substantial contribution to the improvement of the manuscript. All authors have read and agreed to the published version of the manuscript.

Funding: This study was supported by the Fundamental Research Funds for the Central Universities of Central South University [Grant number 2020zzts815].

Institutional Review Board Statement: The study was conducted according to the guidelines of the Declaration of Helsinki and approved by the Ethics Committee of the Xiangya School of Public Health, Central South University (XYGW-2019-025).

Informed Consent Statement: Informed consent was obtained from all students' parents or caregivers involved in the study.

Data Availability Statement: The data that support the findings of this study are not publicly available due to the data containing information that could compromise participant privacy but are available from the corresponding author on reasonable request.

Acknowledgments: We would like to thank the teachers and students from Xiangya School of Public Health, Central South University, in Changsha, China, for their involvement in this investigation. We would appreciate the Changsha Education Bureau for their negotiation with the middle schools. We are also grateful to teachers and leaders from the middle schools for their supports.

Conflicts of Interest: The authors declare no conflict of interest. The funders had no role in the study's design, in the collection, analyses, or interpretation of data, in the writing of the manuscript, or in the decision to publish the results.

\section{Appendix A}

Table A1. Food item, weight, and free sugars from China CDC.

\begin{tabular}{cccc}
\hline Food Descriptor & Quantity & Types & Free Sugars (g) \\
\hline Sodas & $100 \mathrm{~mL}$ & 9 & 9.79 \\
Bubble tea & $100 \mathrm{~mL}$ & 7 & 7.89 \\
Tea drinks & $100 \mathrm{~mL}$ & 6 & 4.31 \\
Fruit or natural juice & $100 \mathrm{~mL}$ & 21 & 10.47 \\
Vegetable protein beverage & $100 \mathrm{~mL}$ & 19 & 7.14 \\
Sports drink & $100 \mathrm{~mL}$ & 6 & 8.22 \\
Flavored milk/yogurt & $100 \mathrm{~mL}$ & 29 & 12.28 \\
Biscuits, cakes & $100 \mathrm{~g}$ & 118 & 17.50 \\
Chocolate, confectionery & $100 \mathrm{~g}$ & 14 & 44.63 \\
Fruit preserves & $100 \mathrm{~g}$ & 12 & 55.04 \\
Honey & $100 \mathrm{~g}$ & 2 & 73.00 \\
\hline
\end{tabular}


Table A2. Sensitivity analysis of the association between characteristics and EDS of the adolescents $(\mathrm{n} \%)$.

\begin{tabular}{|c|c|c|c|c|c|c|}
\hline \multirow{2}{*}{ Variables } & \multicolumn{2}{|c|}{ Original } & \multirow{2}{*}{$p$} & \multicolumn{2}{|c|}{ Imputed } & \multirow{2}{*}{$p$} \\
\hline & No EDS & EDS & & No EDS & EDS & \\
\hline \multicolumn{2}{|c|}{ Family Monthly Income ${ }^{a}$} & & 0.193 & & & 0.065 \\
\hline Low & $328(80.4)$ & 80 (19.6) & & $482(80.5)$ & $117(19.5)$ & \\
\hline Medium & $280(75.7)$ & $90(24.3)$ & & $414(74.9)$ & $139(25.1)$ & \\
\hline High & $187(75.4)$ & $61(24.6)$ & & $279(76.4)$ & $86(23.6)$ & \\
\hline
\end{tabular}

a Family income level missing of 491 cases. Compared by Chi-square test. EDS: ESS score $\geq 10$. No EDS: ESS score $<10$. Family monthly income: low (<5000 RMB), middle (5000-9000 RMB), high (>9000 RMB). RMB: Renminbi, Chinese official coupons, $1 \mathrm{RMB} \approx 0.15$ USD.

Table A3. Correlates of Sleep by level of EDS ( $n=1517, \%)$.

\begin{tabular}{|c|c|c|c|c|}
\hline Variables & $\begin{array}{c}\text { Total } \\
(n=1517)\end{array}$ & $\begin{array}{c}\text { No EDS } \\
1175(77.5 \%)\end{array}$ & $\begin{array}{c}\text { EDS } \\
342(22.5 \%)\end{array}$ & $p$ \\
\hline \multicolumn{5}{|c|}{ Daily Sleep Duration } \\
\hline \multicolumn{4}{|c|}{ On Workdays } & 0.001 \\
\hline$<6 \mathrm{~h}$ & $145(9.6)$ & $99(68.3)$ & $46(31.7)$ & \\
\hline $6 \sim 8 \mathrm{~h}$ & $1061(69.9)$ & $815(76.8)$ & $246(23.2)$ & \\
\hline$>8 \mathrm{~h}$ & $311(20.5)$ & $261(83.9)$ & $50(16.1)$ & \\
\hline \multicolumn{4}{|l|}{ On Weekends } & 0.048 \\
\hline$<6 \mathrm{~h}$ & $84(5.5)$ & $56(66.7)$ & $28(33.3)$ & \\
\hline $6 \sim 8 \mathrm{~h}$ & $593(39.1)$ & $460(77.6)$ & $133(22.4)$ & \\
\hline$>8 \mathrm{~h}$ & $840(55.4)$ & $659(78.5)$ & $181(21.5)$ & \\
\hline \multicolumn{4}{|c|}{ Self-reported Sleep Quality } & $<0.001$ \\
\hline Low & $284(18.7)$ & $181(63.7)$ & $103(36.3)$ & \\
\hline Moderate & $497(32.8)$ & $384(77.3)$ & $113(22.7)$ & \\
\hline High & $736(48.5)$ & $610(82.9)$ & $126(17.1)$ & \\
\hline \multicolumn{4}{|l|}{ LPR Symptoms } & $<0.001$ \\
\hline No & $1394(91.9)$ & $1111(79.7)$ & $283(20.3)$ & \\
\hline Yes & $123(8.1)$ & $64(52.0)$ & $59(48.0)$ & \\
\hline \multicolumn{4}{|l|}{ Physical Activity } & 0.716 \\
\hline Low & $445(29.3)$ & $343(77.1)$ & $102(22.9)$ & \\
\hline Medium & $728(48.0)$ & $560(76.9)$ & $168(23.1)$ & \\
\hline High & $344(22.7)$ & $272(79.1)$ & $72(20.9)$ & \\
\hline \multicolumn{4}{|l|}{ Screen Time } & 0.250 \\
\hline$\leq 2 \mathrm{~h}$ & $595(39.2)$ & $470(79.0)$ & $125(21.0)$ & \\
\hline$>2 \mathrm{~h}$ & $922(60.8)$ & 705 (76.5) & $217(23.5)$ & \\
\hline \multicolumn{4}{|l|}{ Sedentary Time } & 0.838 \\
\hline$\leq 8 \mathrm{~h}$ & $1138(75.0)$ & $880(77.3)$ & $258(22.7)$ & \\
\hline$>8 \mathrm{~h}$ & $379(25.0)$ & $295(77.8)$ & $84(22.2)$ & \\
\hline
\end{tabular}

Compared by Chi-square test. EDS: ESS score $\geq 10$. No EDS: ESS score $<10$. LPR symptoms: the RSI $\geq 13$.

Table A4. The scores of each Epworth Sleepiness Scale item by the level of free sugars intake $(n=1517$, mean $\pm \mathrm{SD}$ ).

\begin{tabular}{|c|c|c|c|c|}
\hline \multirow[b]{2}{*}{ Variables } & \multirow[b]{2}{*}{$\begin{array}{c}\text { Total } \\
(n=1517)\end{array}$} & \multicolumn{2}{|c|}{ Intake of Free Sugars } & \multirow[b]{2}{*}{$p$} \\
\hline & & $\begin{array}{l}\leq 50 \mathrm{~g} / \mathrm{d} \\
(n=861)\end{array}$ & $\begin{array}{l}>50 \mathrm{~g} / \mathrm{d} \\
(n=656)\end{array}$ & \\
\hline Sitting and reading & $1.06 \pm 0.84$ & $0.96 \pm 0.80$ & $1.20 \pm 0.77$ & $<0.001$ \\
\hline Watching TV & $0.59 \pm 0.84$ & $0.57 \pm 0.82$ & $0.62 \pm 0.87$ & 0.417 \\
\hline $\begin{array}{l}\text { Sitting, inactive in a public place } \\
\text { (e.g., a theater or a meeting) }\end{array}$ & $0.18 \pm 0.51$ & $0.19 \pm 0.50$ & $0.18 \pm 0.51$ & 0.698 \\
\hline $\begin{array}{l}\text { As a passenger in a car for an hour } \\
\text { without a break }\end{array}$ & $1.59 \pm 1.08$ & $1.58 \pm 1.08$ & $1.60 \pm 1.09$ & 0.649 \\
\hline
\end{tabular}


Table A4. Cont.

\begin{tabular}{|c|c|c|c|c|}
\hline \multirow[b]{2}{*}{ Variables } & \multirow[b]{2}{*}{$\begin{array}{c}\text { Total } \\
(n=1517)\end{array}$} & \multicolumn{2}{|c|}{ Intake of Free Sugars } & \multirow[b]{2}{*}{$p$} \\
\hline & & $\begin{array}{l}\leq 50 \mathrm{~g} / \mathrm{d} \\
(n=861)\end{array}$ & $\begin{array}{c}>50 \mathrm{~g} / \mathrm{d} \\
(n=656)\end{array}$ & \\
\hline $\begin{array}{l}\text { Lying down to rest in the afternoon } \\
\text { when circumstances permit }\end{array}$ & $1.85 \pm 1.11$ & $1.82 \pm 1.12$ & $1.89 \pm 1.09$ & 0.226 \\
\hline Sitting and talking to someone & $0.16 \pm 0.47$ & $0.12 \pm 0.39$ & $0.22 \pm 0.54$ & $<0.001$ \\
\hline $\begin{array}{l}\text { Sitting quietly after a lunch } \\
\text { without alcohol }\end{array}$ & $0.68 \pm 0.89$ & $0.63 \pm 0.87$ & $0.75 \pm 0.91$ & 0.006 \\
\hline $\begin{array}{l}\text { In a car, while stopped for a few } \\
\text { minutes in the traffic }\end{array}$ & $0.67 \pm 0.95$ & $0.62 \pm 0.91$ & $0.74 \pm 0.98$ & 0.009 \\
\hline Total ESS Scores & $6.79 \pm 3.88$ & $6.48 \pm 3.79$ & $7.20 \pm 3.96$ & $<0.001$ \\
\hline
\end{tabular}

Compared by Kruskal Wallis test. ESS: Epworth Sleepiness Scale.

Table A5. Binary logistic regression models on the associations between EDS and consumption frequencies of different free sugars sources (No EDS as the reference, $n=1517$ ).

\begin{tabular}{ccc}
\hline $\begin{array}{c}\text { Variables } \\
\text { ( } \leq \mathbf{1} \text { Time/Week }=\text { ref) }\end{array}$ & Crude OR (95\% CI) & Adjusted OR (95\% CI) \\
\hline SSBs \# & $1.525(1.160,2.005)^{* *}$ & $1.509(1.141,1.996)^{* *}$ \\
Sodas & $1.296(1.000,1.679)$ & $1.244(0.949,1.630)$ \\
Bubble tea & $1.424(1.081,1.876)^{*}$ & $1.297(0.974,1.726)$ \\
Tea drinks & $1.269(0.940,1.714)$ & $1.334(0.974,1.827)$ \\
Fruit or natural juice & $0.990(0.693,1.413)$ & $0.994(0.686,1.441)$ \\
Vegetable protein beverage & $1.460(1.085,1.965)^{*}$ & $1.439(1.054,1.964)^{*}$ \\
Sports drink & $0.975(0.633,1.500)$ & $0.948(0.602,1.494)$ \\
Flavored milk/yogurt & $1.184(0.927,1.513)$ & $1.199(0.930,1.545)$ \\
Cakes and Desserts & $1.333(1.017,1.748)^{*}$ & $1.312(0.990,1.740)$ \\
Confectionery & $1.613(1.241,2.097) * * *$ & $1.548(1.178,2.035)^{* *}$ \\
Fruit preserves & $1.018(0.705,1.471)$ & $0.974(0.665,1.425)$ \\
Honey & $1.432(0.932,2.201)$ & $1.398(0.890,2.196)$ \\
\hline$\#: \leq 4$ times/week $=$ ref. ${ }^{* * *} p<0.001, * * p<0.01$, and $* p<0.05$. EDS: the ESS score $\geq 10$. No EDS: the ESS \\
score $<10$. Adjusted by students' age, sex, BMI status, sleep duration, and self-reported sleep quality.
\end{tabular}

\section{References}

1. $\quad$ Bittencourt, L.R.; Silva, R.S.; Santos, R.F.; Pires, M.L.; Mello, M.T. Excessive daytime sleepiness. Braz. J. Psychiatry 2005, 27 (Suppl. 1), 16-21. [CrossRef] [PubMed]

2. Bixler, E.O.; Vgontzas, A.N.; Lin, H.M.; Calhoun, S.L.; Vela-Bueno, A.; Kales, A. Excessive daytime sleepiness in a general population sample: The role of sleep apnea, age, obesity, diabetes, and depression. J. Clin. Endocrinol. Metab. 2005, 90, $4510-4515$. [CrossRef] [PubMed]

3. Vashum, K.P.; McEvoy, M.A.; Hancock, S.J.; Islam, M.R.; Peel, R.; Attia, J.R.; Milton, A.H. Prevalence of and associations with excessive daytime sleepiness in an Australian older population. Asia Pac. J. Public Health 2015, 27, Np2275-Np2284. [CrossRef] [PubMed]

4. Kaneita, Y.; Ohida, T.; Uchiyama, M.; Takemura, S.; Kawahara, K.; Yokoyama, E.; Miyake, T.; Harano, S.; Suzuki, K.; Yagi, Y.; et al. Excessive daytime sleepiness among the Japanese general population. J. Epidemiol. 2005, 15, 1-8. [CrossRef]

5. Hayley, A.C.; Williams, L.J.; Kennedy, G.A.; Berk, M.; Brennan, S.L.; Pasco, J.A. Prevalence of excessive daytime sleepiness in a sample of the Australian adult population. Sleep Med. 2014, 15, 348-354. [CrossRef]

6. Chung, K.F.; Cheung, M.M. Sleep-wake patterns and sleep disturbance among Hong Kong Chinese adolescents. Sleep 2008, 31, 185-194. [CrossRef]

7. Gibson, E.S.; Powles, A.C.; Thabane, L.; O’Brien, S.; Molnar, D.S.; Trajanovic, N.; Ogilvie, R.; Shapiro, C.; Yan, M.; Chilcott-Tanser, L. "Sleepiness" is serious in adolescence: Two surveys of 3235 Canadian students. BMC Public Health $2006,6,116$. [CrossRef]

8. Luo, C.; Zhang, J.; Chen, W.; Lu, W.; Pan, J. Course, risk factors, and mental health outcomes of excessive daytime sleepiness in rural Chinese adolescents: A one-year prospective study. J. Affect. Disord. 2018, 231, 15-20. [CrossRef]

9. Fallone, G.; Owens, J.A.; Deane, J. Sleepiness in children and adolescents: Clinical implications. Sleep Med. Rev. 2002, 6, 287-306. [CrossRef]

10. Raine, A.; Venables, P.H. Adolescent daytime sleepiness as a risk factor for adult crime. J. Child Psychol. Psychiatry 2017, 58, 728-735. [CrossRef] 
11. de Souza Vilela, T.; Bittencourt, L.R.; Tufik, S.; Moreira, G.A. Factors influencing excessive daytime sleepiness in adolescents. J. Pediatr. (Rio J.) 2016, 92, 149-155. [CrossRef]

12. Oginska, H.; Pokorski, J. Fatigue and mood correlates of sleep length in three age-social groups: School children, students, and employees. Chronobiol. Int. 2006, 23, 1317-1328. [CrossRef]

13. Dashti, H.S.; Scheer, F.A.; Jacques, P.F.; Lamon-Fava, S.; Ordovás, J.M. Short sleep duration and dietary intake: Epidemiologic evidence, mechanisms, and health implications. Adv. Nutr. 2015, 6, 648-659. [CrossRef]

14. Panossian, L.A.; Veasey, S.C. Daytime sleepiness in obesity: Mechanisms beyond obstructive sleep apnea-A review. Sleep 2012, 35, 605-615. [CrossRef]

15. McClain, J.J.; Lewin, D.S.; Laposky, A.D.; Kahle, L.; Berrigan, D. Associations between physical activity, sedentary time, sleep duration and daytime sleepiness in US adults. Prev. Med. 2014, 66, 68-73. [CrossRef]

16. Adams, R.J.; Appleton, S.L.; Vakulin, A.; Lang, C.; Martin, S.A.; Taylor, A.W.; McEvoy, R.D.; Antic, N.A.; Catcheside, P.G.; Wittert, G.A. Association of daytime sleepiness with obstructive sleep apnoea and comorbidities varies by sleepiness definition in a population cohort of men. Respirology 2016, 21, 1314-1321. [CrossRef]

17. Santiago, G.T.P.; de Menezes Galvão, A.C.; de Almeida, R.N.; Mota-Rolim, S.A.; Palhano-Fontes, F.; Maia-de-Oliveira, J.P.; de Araújo, D.B.; Lobão-Soares, B.; Galvão-Coelho, N.L. Changes in Cortisol but Not in Brain-Derived Neurotrophic Factor Modulate the Association Between Sleep Disturbances and Major Depression. Front. Behav. Neurosci. 2020, 14, 44. [CrossRef]

18. Anderson, C.; Horne, J.A. A high sugar content, low caffeine drink does not alleviate sleepiness but may worsen it. Hum. Psychopharmacol. 2006, 21, 299-303. [CrossRef]

19. Katagiri, R.; Asakura, K.; Kobayashi, S.; Suga, H.; Sasaki, S. Low intake of vegetables, high intake of confectionary, and unhealthy eating habits are associated with poor sleep quality among middle-aged female Japanese workers. J. Occup. Health 2014, 56, 359-368. [CrossRef]

20. St-Onge, M.P.; Roberts, A.; Shechter, A.; Choudhury, A.R. Fiber and Saturated Fat Are Associated with Sleep Arousals and Slow Wave Sleep. J. Clin. Sleep Med. 2016, 12, 19-24. [CrossRef]

21. World Health Organization. Guideline: Sugars Intake for Adults and Children; World Health Organization: Geneva, Swizerland, 2015.

22. Azaïs-Braesco, V.; Sluik, D.; Maillot, M.; Kok, F.; Moreno, L.A. A review of total \& added sugar intakes and dietary sources in Europe. Nutr. J. 2017, 16, 6. [CrossRef]

23. Liu, S. The Status and Change of Sugary Food Consumption and its Relationship with Overweight and Obesity in Chinese Residents during 2002-2012; Postgraduate, Chinese Center for Disease Control and Prevention: Beijing, China, 2016.

24. Yang, Q.; Xi, Y.; Liu, H.; Luo, J.; Ouyang, Y.; Sun, M.; Yong, C.; Xiang, C.; Lin, Q. Free Sugars Intake among Chinese Adolescents and Its Association with Dental Caries: A Cross-Sectional Study. Nutrients 2021, 13, 765. [CrossRef]

25. Paglia, L. The sweet danger of added sugars. Eur. J. Paediatr. Dent. 2019, 20, 89. [CrossRef]

26. Hong, J.; Whelton, H.; Douglas, G.; Kang, J. Consumption frequency of added sugars and UK children's dental caries. Community Dent. Oral. Epidemiol. 2018, 46, 457-464. [CrossRef]

27. Moynihan, P. Sugars and Dental Caries: Evidence for Setting a Recommended Threshold for Intake. Adv. Nutr. 2016, 7, 149-156. [CrossRef]

28. Okuda, M.; Fujiwara, A.; Sasaki, S. Added and Free Sugars Intake and Metabolic Biomarkers in Japanese Adolescents. Nutrients 2020, 12, 2046. [CrossRef]

29. Buyken, A.E.; Mitchell, P.; Ceriello, A.; Brand-Miller, J. Optimal dietary approaches for prevention of type 2 diabetes: A life-course perspective. Diabetologia 2010, 53, 406-418. [CrossRef]

30. Mahoney, L.T.; Burns, T.L.; Stanford, W.; Thompson, B.H.; Witt, J.D.; Rost, C.A.; Lauer, R.M. Coronary risk factors measured in childhood and young adult life are associated with coronary artery calcification in young adults: The Muscatine Study. J. Am. Coll. Cardiol. 1996, 27, 277-284. [CrossRef]

31. Bartel, K.A.; Gradisar, M.; Williamson, P. Protective and risk factors for adolescent sleep: A meta-analytic review. Sleep Med. Rev. 2015, 21, 72-85. [CrossRef]

32. Jun, N.; Lee, A.; Baik, I. Associations of Caffeinated Beverage Consumption and Screen Time with Excessive Daytime Sleepiness in Korean High School Students. Clin. Nutr. Res. 2017, 6, 55-60. [CrossRef]

33. Oliver, G.; Wardle, J.; Gibson, E.L. Stress and food choice: A laboratory study. Psychosom. Med. 2000, 62, 853-865. [CrossRef] [PubMed]

34. Gibson, E.L. Emotional influences on food choice: Sensory, physiological and psychological pathways. Physiol. Behav. 2006, 89, 53-61. [CrossRef] [PubMed]

35. Kampov-Polevoy, A.B.; Alterman, A.; Khalitov, E.; Garbutt, J.C. Sweet preference predicts mood altering effect of and impaired control over eating sweet foods. Eat Behav. 2006, 7, 181-187. [CrossRef] [PubMed]

36. Li, F.; Lin, Q.; Yang, Q.; Xi, Y.; Liu, H.; Luo, J.; Ouyang, Y.; Sun, M.; Yong, C.; Xiang, C.; et al. The Association between Free Sugars Consumption and Laryngopharyngeal Reflux: A Cross-Sectional Study among Chinese Adolescents. Nutrients 2021, $13,3012$. [CrossRef] [PubMed]

37. Chen, N.H.; Johns, M.W.; Li, H.Y.; Chu, C.C.; Liang, S.C.; Shu, Y.H.; Chuang, M.L.; Wang, P.C. Validation of a Chinese version of the Epworth sleepiness scale. Qual. Life Res. 2002, 11, 817-821. [CrossRef]

38. Johns, M.W. A new method for measuring daytime sleepiness: The Epworth sleepiness scale. Sleep 1991, 14, 540-545. [CrossRef] 
39. Barbé, F.; Durán-Cantolla, J.; Sánchez-de-la-Torre, M.; Martínez-Alonso, M.; Carmona, C.; Barceló, A.; Chiner, E.; Masa, J.F.; Gonzalez, M.; Marín, J.M.; et al. Effect of Continuous Positive Airway Pressure on the Incidence of Hypertension and Cardiovascular Events in Nonsleepy Patients With Obstructive Sleep Apnea: A Randomized Controlled Trial. JAMA 2012, 307, 2161-2168. [CrossRef]

40. Lee, P.H.; Macfarlane, D.J.; Lam, T.H.; Stewart, S.M. Validity of the International Physical Activity Questionnaire Short Form (IPAQ-SF): A systematic review. Int. J. Behav. Nutr. Phys. Act. 2011, 8, 115. [CrossRef]

41. World Health Organization. Global Action Plan on Physical Activity 2018-2030: More Active People for a Healthier World; World Health Organization: Geneva, Swizerland, 2018.

42. Belafsky, P.C.; Postma, G.N.; Koufman, J.A. Validity and reliability of the reflux symptom index (RSI). J. Voice 2002, 16, 274-277. [CrossRef]

43. National Health and Family Planning Commission of the People's Republic of China (Ed.) Screening for Overweight and Obesity among School-Age Children and Adolescents; WS/T 586-2018; National Health and Family Planning Commission of the People's China: Beijing, China, 2018.

44. National Health and Family Planning Commission of the People's Republic of China (Ed.) High Waist Circumference Screening Threshold Among Children and Adolescents Aged 7 18 Years; WS/T 611-2018; National Health and Family Planning Commission of the People's Republic of China: Beijing, China, 2018.

45. The Chinese Nutrition Society. The Food Guide Pagoda for Chinese Residents; The Chinese Nutrition Society: Beijing, China, 2016.

46. Alves, F.R.; de Souza, E.A.; de França Ferreira, L.G.; de Oliveira Vilar Neto, J.; de Bruin, V.M.S.; de Bruin, P.F.C. Sleep duration and daytime sleepiness in a large sample of Brazilian high school adolescents. Sleep Med. 2020, 66, 207-215. [CrossRef]

47. Nathan, N.; Zeitzer, J. A survey study of the association between mobile phone use and daytime sleepiness in California high school students. BMC Public Health 2013, 13, 840. [CrossRef]

48. Shin, C.; Kim, J.; Lee, S.; Ahn, Y.; Joo, S. Sleep habits, excessive daytime sleepiness and school performance in high school students. Psychiatry Clin. Neurosci. 2003, 57, 451-453. [CrossRef]

49. Liu, Y.; Zhang, J.; Li, S.X.; Chan, N.Y.; Yu, M.W.M.; Lam, S.P.; Chan, J.W.Y.; Li, A.M.; Wing, Y.K. Excessive daytime sleepiness among children and adolescents: Prevalence, correlates, and pubertal effects. Sleep Med. 2019, 53, 1-8. [CrossRef]

50. Wang, Z.Y.; Liu, Z.Z.; Jia, C.X.; Liu, X. Age at menarche, menstrual problems, and daytime sleepiness in Chinese adolescent girls. Sleep 2019, 42, zsz061. [CrossRef]

51. Owens, J. Insufficient sleep in adolescents and young adults: An update on causes and consequences. Pediatrics 2014, 134, e921-932. [CrossRef]

52. Melaku, Y.A.; Reynolds, A.C.; Gill, T.K.; Appleton, S.; Adams, R. Association between Macronutrient Intake and Excessive Daytime Sleepiness: An Iso-Caloric Substitution Analysis from the North West Adelaide Health Study. Nutrients 2019, 11, 2374. [CrossRef]

53. Morrissey, B.; Allender, S.; Strugnell, C. Dietary and Activity Factors Influence Poor Sleep and the Sleep-Obesity Nexus among Children. Int. J. Env. Res. Public Health 2019, 16, 1778. [CrossRef]

54. Kjeldsen, J.S.; Hjorth, M.F.; Andersen, R.; Michaelsen, K.F.; Tetens, I.; Astrup, A.; Chaput, J.P.; Sjödin, A. Short sleep duration and large variability in sleep duration are independently associated with dietary risk factors for obesity in Danish school children. Int. J. Obes. (Lond.) 2014, 38, 32-39. [CrossRef]

55. Beebe, D.W.; Simon, S.; Summer, S.; Hemmer, S.; Strotman, D.; Dolan, L.M. Dietary intake following experimentally restricted sleep in adolescents. Sleep 2013, 36, 827-834. [CrossRef]

56. Sampasa-Kanyinga, H.; Hamilton, H.A.; Chaput, J.P. Sleep duration and consumption of sugar-sweetened beverages and energy drinks among adolescents. Nutrition 2018, 48, 77-81. [CrossRef]

57. Chen, T.; Wu, Z.; Shen, Z.; Zhang, J.; Shen, X.; Li, S. Sleep duration in Chinese adolescents: Biological, environmental, and behavioral predictors. Sleep Med. 2014, 15, 1345-1353. [CrossRef]

58. Scholz-Ahrens, K.E.; Ahrens, F.; Barth, C.A. Nutritional and health attributes of milk and milk imitations. Eur. J. Nutr. 2020, 59, 19-34. [CrossRef]

59. Chauhan, A.; Chauhan, V. Beneficial Effects of Walnuts on Cognition and Brain Health. Nutrients 2020, 12, 550. [CrossRef]

60. An-xu, W.; Yong-xian, W.; Jie, G.; Jing, S.; Jun-sheng, H. A Randomized, Double-Blind, Placebo-Controlled Study of Walnut Supplementation on Memory Performance in Middle School Students. China Food Addit. 2018, 009, 101-106.

61. Ellis, D.; Lieb, J. Hyperoxaluria and Genitourinary Disorders in Children Ingesting Almond Milk Products. J. Pediatr. 2015, 167, 1155-1158. [CrossRef]

62. St-Onge, M.P.; Mikic, A.; Pietrolungo, C.E. Effects of Diet on Sleep Quality. Adv. Nutr. 2016, 7, 938-949. [CrossRef]

63. Zeng, Y.; Yang, J.; Du, J.; Pu, X.; Yang, X.; Yang, S.; Yang, T. Strategies of Functional Foods Promote Sleep in Human Being. Curr. Signal Transduct. Ther. 2014, 9, 148-155. [CrossRef]

64. Morin, C.M.; Bjorvatn, B.; Chung, F.; Holzinger, B.; Partinen, M.; Penzel, T.; Ivers, H.; Wing, Y.K.; Chan, N.Y.; Merikanto, I.; et al. Insomnia, anxiety, and depression during the COVID-19 pandemic: An international collaborative study. Sleep Med. 2021, 87, 38-45. [CrossRef]

65. Naughton, F.; Ward, E.; Khondoker, M.; Belderson, P.; Marie Minihane, A.; Dainty, J.; Hanson, S.; Holland, R.; Brown, T.; Notley, C. Health behaviour change during the UK COVID-19 lockdown: Findings from the first wave of the C-19 health behaviour and well-being daily tracker study. Br. J. Health Psychol. 2021, 26, 624-643. [CrossRef] 
66. McCarthy, H.; Potts, H.W.W.; Fisher, A. Physical Activity Behavior Before, During, and After COVID-19 Restrictions: Longitudinal Smartphone-Tracking Study of Adults in the United Kingdom. J. Med. Internet Res. 2021, 23, e23701. [CrossRef]

67. Al-Musharaf, S. Prevalence and Predictors of Emotional Eating among Healthy Young Saudi Women during the COVID-19 Pandemic. Nutrients 2020, 12, 2923. [CrossRef] [PubMed]

68. Jia, P.; Liu, L.; Xie, X.; Yuan, C.; Chen, H.; Guo, B.; Zhou, J.; Yang, S. Changes in dietary patterns among youths in China during COVID-19 epidemic: The COVID-19 impact on lifestyle change survey (COINLICS). Appetite 2021, 158, 105015. [CrossRef] [PubMed]

69. Lamarche, B.; Brassard, D.; Lapointe, A.; Laramée, C.; Kearney, M.; Côté, M.; Bélanger-Gravel, A.; Desroches, S.; Lemieux, S.; Plante, C. Changes in diet quality and food security among adults during the COVID-19-related early lockdown: Results from NutriQuébec. Am. J. Clin. Nutr. 2021, 113, 984-992. [CrossRef] [PubMed]

70. Sadler, J.R.; Thapaliya, G.; Jansen, E.; Aghababian, A.H.; Smith, K.R.; Carnell, S. COVID-19 Stress and Food Intake: Protective and Risk Factors for Stress-Related Palatable Food Intake in U.S. Adults. Nutrients 2021, 13, 901. [CrossRef]

71. Yu, B.; Zhang, D.; Yu, W.; Luo, M.; Yang, S.; Jia, P. Impacts of lockdown on dietary patterns among youths in China: The COVID-19 Impact on Lifestyle Change Survey. Public Health Nutr. 2021, 24, 3221-3232. [CrossRef]

72. de Araújo, T.A.; Mota, M.C.; Crispim, C.A. Obesity and sleepiness in women with fibromyalgia. Rheumatol. Int. 2015, 35, $281-287$. [CrossRef]

73. Hayley, A.C.; Williams, L.J.; Kennedy, G.A.; Berk, M.; Brennan, S.L.; Pasco, J.A. Excessive daytime sleepiness and body composition: A population-based study of adults. PLOS ONE 2014, 9, e112238. [CrossRef]

74. Peach, H.; Gaultney, J.F.; Reeve, C.L. Sleep characteristics, body mass index, and risk for hypertension in young adolescents. J. Youth Adolesc. 2015, 44, 271-284. [CrossRef]

75. Maugeri, A.; Medina-Inojosa, J.R.; Kunzova, S.; Agodi, A.; Barchitta, M.; Sochor, O.; Lopez-Jimenez, F.; Geda, Y.E.; Vinciguerra, M. Sleep Duration and Excessive Daytime Sleepiness Are Associated with Obesity Independent of Diet and Physical Activity. Nutrients 2018, 10, 1219. [CrossRef]

76. Vgontzas, A.N.; Fernandez-Mendoza, J.; Miksiewicz, T.; Kritikou, I.; Shaffer, M.L.; Liao, D.; Basta, M.; Bixler, E.O. Unveiling the longitudinal association between short sleep duration and the incidence of obesity: The Penn State Cohort. Int. J. Obes. (Lond.) 2014, 38, 825-832. [CrossRef]

77. Knutson, K.L. Sex differences in the association between sleep and body mass index in adolescents. J. Pediatr. 2005, 147, 830-834. [CrossRef]

78. Levinson, P.D.; McGarvey, S.T.; Carlisle, C.C.; Eveloff, S.E.; Herbert, P.N.; Millman, R.P. Adiposity and cardiovascular risk factors in men with obstructive sleep apnea. Chest 1993, 103, 1336-1342. [CrossRef] 